\title{
Screening of microdeletions of chromosome 20 in patients with Alagille syndrome
}

\author{
C Desmaze, J F Deleuze, A M Dutrillaux, G Thomas, M Hadchouel, A Aurias
}

\begin{abstract}
We report a cytogenetic and molecular study of a series of patients with Alagille syndrome. All 14 patients were studied with high resolution banding techniques and eight of them were also analysed with non-radioactive in situ hybridisation of the cosmid probe D20S6. Seven of these eight patients were also studied for allelic losses at the D20S6 locus. No microdeletion of chromosome 20 was found in this series.
\end{abstract}

There is now evidence that interstitial deletions of the short arm of chromosome 20 are associated with the main signs of arteriohepatic dysplasia (Alagille syndrome). Up to now, 15 cases of patients with $20 \mathrm{p}$ deletion, ascertained for malformations, have been published. With one exception, all these cases showed clinical features of Alagille syndrome (for reviews see Zhang $e t a l^{1}$ and Anad $e t a l^{2}$ ). Furthermore, a percentage of patients with Alagille syndrome exhibit a deletion of a segment of $20 \mathrm{p}^{134}$ These findings strongly suggest that Alagille syndrome is a consequence of an interstitial deletion of chromosome 20 leading to the loss of several adjacent genes. Thus, this syndrome probably belongs to the group of 'contiguous gene syndromes'.56

In a previous study, ${ }^{1}$ we showed that among 21 patients with Alagille syndrome, one exhibited a small deletion of bands $20 \mathrm{p} 11.23$ to p12.3. In this patient and in the patient reported by Schnittger et $a l^{3}{ }^{3}$ the deletions were studied further by in situ hybridisation on chromosomes and for allelic losses in the DNA. Among the six loci tested, three (D20S5, PRIP, and $S C G 1$ ) were conserved in at least one patient and are probably not involved in the genesis of the disorder. The three other loci were lost in our patient. These loci can thus be used as potential probes for the search for molecular deletions in affected patients. From the cytogenetic data (review in Anad et $a l^{2}$ ), it appears that the critical region of the short arm of chromosome 20 probably lies in band p12. Among the loci lost in our patient, D20S6 had been previously localised in this band by radioactive in situ hybridisation on metaphase chromosomes. ${ }^{7}$ Before using this probe for routine screening for microdeletions in our patients, we refined its localisation by non-radioactive fluorescent in situ hybridisation. Among the 14 new patients reported here, eight have thus been studied with non-radioactive in situ hybridisation of a cosmid probe corresponding to D20S6. Seven of these patients were further screened for allelic losses at this locus.

\section{Material and methods}

Blood samples were obtained from 16 patients with Alagille syndrome. Clinical data have been previously published, ${ }^{8}$ but these patients had not been studied at the chromosomal or the molecular level.

\section{CYTOGENETIC PREPARATIONS}

For high resolution chromosome analysis, prometaphases were obtained from PHA stimulated lymphocytes after thymidine synchronisation of the culture and BrdU incorporation $(10 \mu \mathrm{g} / \mathrm{ml})$ during the last seven hours. Colcemid block was reduced to $30 \mathrm{mi}-$ nutes. For in situ hybridisation, metaphases were obtained after BrdU incorporation $(20 \mu \mathrm{g} / \mathrm{ml})$ during the last seven hours and a colcemid block of two hours.

\section{PROBES}

The cosmid probe $\mathrm{CD} 3 \mathrm{H} 12$ was isolated from a cosmid library of total human DNA after screening with an insert corresponding to D20S6 (plasmid pD3H12) as previously described. ${ }^{8}$ For the allelic studies, DNA from the patients, digested with the enzyme TaqI, was probed, on Southern blots, with the probe pD3H12, which is known to exhibit polymorphic bands at $13 \cdot 1$ or $8 \cdot 6 / 4.5 \mathrm{~kb}$.

\section{IN SITU HYBRIDISATION}

The slides were treated with RNAse $(100 \mu \mathrm{g} /$ $\mathrm{ml}$ ) for one hour at $37^{\circ} \mathrm{C}$, rinsed three times in $2 \times$ SSC, pH 7 (10 minutes each), and dehydrated in a series of $50 \%, 75 \%$, and $100 \%$ ethanol baths (10 minutes each). Slides were denatured in $70 \%$ formamide in $2 \times \mathrm{SSC}$ at $70^{\circ} \mathrm{C}$ for two minutes. They were dipped in ice cold $2 \times$ SSC and dehydrated in the same ethanol baths kept at $0^{\circ} \mathrm{C}$.

The cosmid DNA was labelled by nick translation with digoxigenin-11-dUTP (Boehringer). The probe (final concentration $1 \mu \mathrm{g} / \mathrm{ml}$ ) and sonicated human DNA (final concentration $100 \mu \mathrm{g} / \mathrm{ml})$ in hybridisation buffer $(2 \times \mathrm{SSC}$, $20 \mathrm{mmol} / \mathrm{l} \mathrm{Na} 2 \mathrm{HPO} 4,20 \mathrm{mmol} \mathrm{NaH} 2 \mathrm{PO} 4$, $50 \%$ deionised formamide, $10 \%$ dextran sulphate, $0 \cdot 1 \%$ SDS, $1 \%$ Denhardt's solution) were denatured in boiling water for $10 \mathrm{mi}-$ nutes. Immediately after this denaturation, $20 \mu \mathrm{l}$ per slide were spotted on the cytogenetic spread. The slides were then incubated overnight at $42^{\circ} \mathrm{C}$ in a moist chamber under a plastic coverslip. They were washed twice in $50 \%$ formamide, $2 \times \mathrm{SSC}$ and then twice in $2 \times \mathrm{SSC}$, five minutes at $42^{\circ} \mathrm{C}$ each, and 10 minutes in PBS, $0.1 \%$ Tween $20,1 \%$ BSA. 
The slides were then incubated for 45 minutes at $37^{\circ} \mathrm{C}$ after addition of $40 \mu \mathrm{l}$ of a $1: 8$ dilution of an antidigoxigenin FITC conjugated antibody. They were rinsed in PBS, $0.1 \%$ Tween 20 and counterstained with $50 \mu \mathrm{l}$ of $0.3 \mu \mathrm{g} / \mathrm{ml}$ propidium iodide solution. The slides were photographed on a photomicroscope II Zeiss with an Ektachrome 400 film. For some patients, an alkaline phosphatase conjugated antibody was also used, as previously described by Zhang et al. ${ }^{9}$

\section{Results}

CHROMOSOMAL ANALYSES

Among the 14 new patients analysed with high resolution banding techniques, no structural chromosomal aberration was observed and in particular no microdeletion of the short arm of chromosome 20 was found.

\section{IN SITU HYBRIDISATION}

Localisation of the locus D20S6

The signal was shown through an FITC conjugated antibody. The slides were further treated with $\mathrm{R}$ banding and the same mitoses were photographed (fig 1). A total of 81 spots was observed. Among them, 50 were located in band p12.3, 19 were at the level of sub-band p12.2, and 12 were more proximal in band p12.1 (fig 2). From these data, we conclude that D20S6 lies in the distal part of band p12 (p12.2 to p12.3).

\section{Screening of microdeletions}

The hybridisation efficiency of this cosmid probe is high since all metaphases examined exhibited specific signals as previously

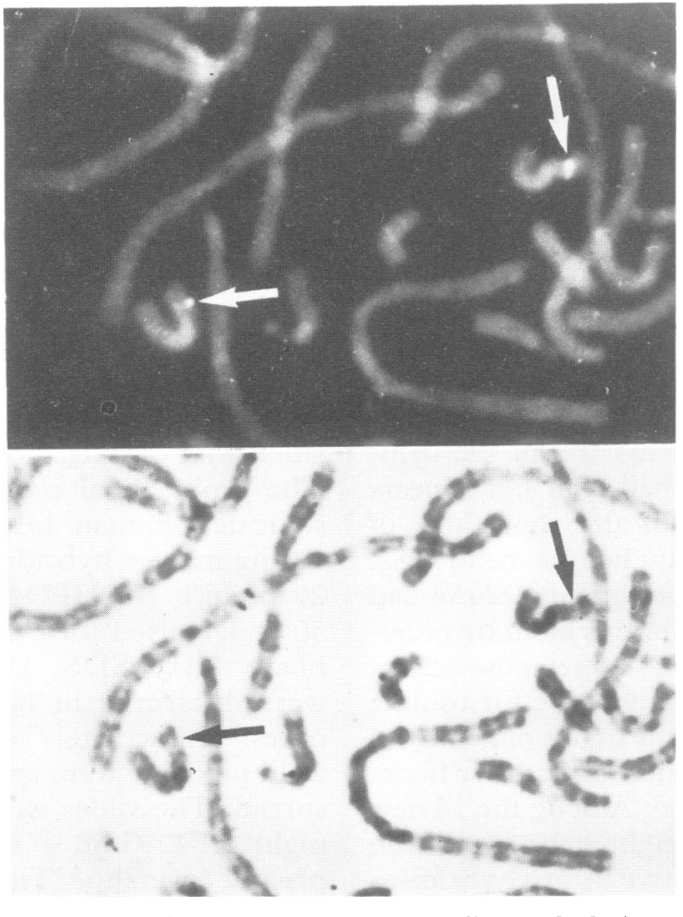

Figure 1 Fluorescent spots corresponding to the loci D20S6 were located on prometaphase chromosomes after high resolution $R$ banding.

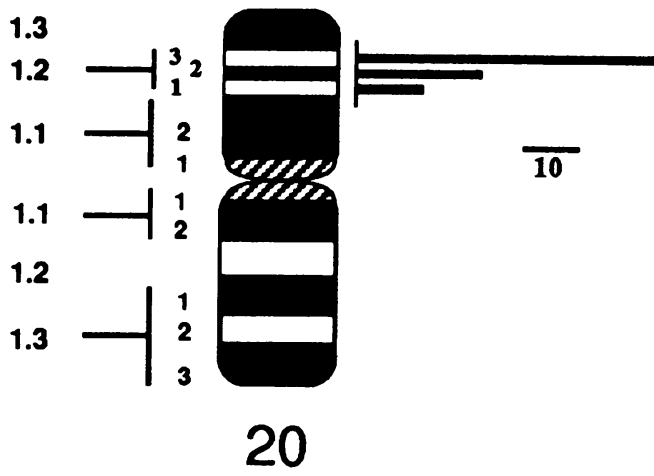

Figure 2 Schematic representation of the in situ hybridisation data. The scale represents 10 fluorescent spots.

quoted. ${ }^{9}$ Furthermore, about $70 \%$ of the metaphases possessed signals on both homologues, indicating that both loci D20S6 were present in the cells (fig 3 ). In this series of 10 patients, specific signals were always observed on both homologues, showing that none of the patients was hemizygous for the locus D20S6.

Allelic losses

Seven of these eight patients were screened by Southern blotting for allelic losses at the D20S6 locus. In this series, there was no evidence of hemizygosity and the genotypes of all patients at D20S6 were fully compatible with those of their parents (table). However, only two of these seven patients were heterozygous at this locus and thus certainly not deleted for this DNA segment.

\section{Discussion}

Only a few cytogenetic studies in Alagille syndrome have been reported and the frequency of deletions of $20 \mathrm{p}$ is not known. We

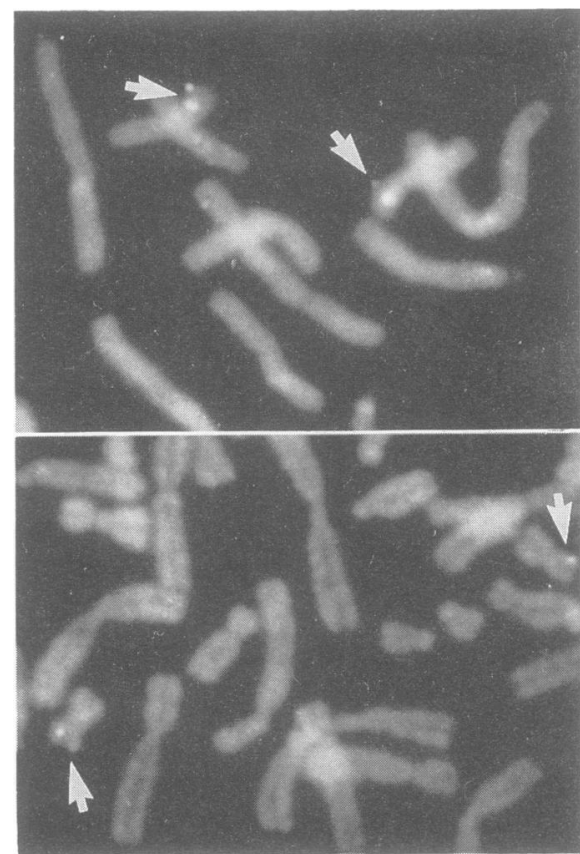

Figure 3 Partial metaphases from two patients exhibiting specific signals on both homologues. 
Genotypes of the patients and of their parents at the locus D20S6: $1=$ the $13 \cdot 1 \mathrm{~kb}$ band, $2=$ the two $8 \cdot 6 / 4 \cdot 5 \mathrm{~kb}$ bands

\begin{tabular}{lccc}
\hline Cases & Patients & Mothers & Fathers \\
\hline 1 & 1 & 1,2 & 1,2 \\
2 & 1 & 1 & - \\
3 & 2 & - & 1,2 \\
4 & 1 & 1,2 & - \\
5 & 1,2 & 2 & - \\
6 & 1 & 1 & - \\
7 & 1,2 & 1,2 & 1,2 \\
\hline
\end{tabular}

report a new series of 14 patients with Alagille syndrome studied using high resolution banding for allelic losses in DNA. Eight of these patients were also studied using non-radioactive in situ hybridisation with a cosmid probe corresponding to D20S6. When combined with our previously published series of 21 patients, only one deletion, shown by chromosomes analysis, in situ hybridisation, and allelic studies, was found. From these data, it appears that the frequency of $20 p$ deletions detectable at the cytogenetic level is low. If this disorder belongs to the group of contiguous gene syndromes, our data indicate that the locus D20S6 is probably not involved in the minimal deletion theoretically present in all patients. Nevertheless, we show here that fluorescent in situ hybridisation is now available for routine studies and that this technique is particularly favourable for the screening of microdeletions, especially when studies of DNA polymorphisms are inconclusive.

This work was supported in part by grants from the Sociéte Française du Cancer. CD is recipient of a fellowship from the Ligue Nationale Contre le Cancer and JFD of a fellowship from the SESEP.

1 Zhang F, Deleuze JF, Aurias A, et al. Interstitial deletion of the short arm of chromosome 20 in arteriohepatic dysplasia the short arm of chromosome 20 in arteriohepatic dysplasia (Alagille syndrome). $\mathcal{F}$ Pediatr 1990;116:73-7.
Anad F, Burn J, Matthews D, et al. Alagille syndrome and deletion of 20p. ₹ Med Genet 1990;27:729-37.

3 Schnittger S, Höfers C, Heidemann P, Beermann F Hansmann I. Molecular and cytogenetic analysis of an interstitial 20p deletion associated with syndromic intrahepatic ductular hypoplasia (Alagille syndrome). Hum Genet 1989;83:239-44.

4 Byrne JLB, Harrod MJE, Friedman JM, Howard-Peebles PN. Del(20p) with manifestations of arteriohepatic dysplasia. Am I Med Genet 1986;24:673-8.

5 Schmickel RD. Contiguous gene syndromes: a component of recognizable syndromes. $\mathcal{F}$ Pediatr 1986;109:231-41.

6 Emanuel BS. Molecular cytogenetics toward dissection of the contiguous gene syndromes. Am $f$ Hum Genet 1988 43:575-8.

7 Goodfellow PJ, Duncan AMV, Farrer LA, et al. Localization and linkage of three polymorphic DNA sequences on human chromosome 20. Cytogenet Cell Genet 1987; 44:112-7.

8 Alagille D, Estrada A, Hadchouel M, et al. Syndromic paucity of interlobular ducts (Alagille syndrome or arterio1987;110:195-200.

9 Zhang F, Heilig R, Thomas G, Aurias A. A one-step efficien and specific non-radioactive non-fluorescent method for in situ hybridization of banded chromosomes. Chromosoma 1990;99:436-9. 